\title{
Ending preventable child deaths from pneumonia and diarrhoea by 2025. Development of the integrated Global Action Plan for the Prevention and Control of Pneumonia and Diarrhoea
}

\author{
Shamim Qazi, ${ }^{1}$ Samira Aboubaker, ${ }^{1}$ Rachel MacLean, ${ }^{2}$ Olivier Fontaine, ${ }^{3}$ \\ Carsten Mantel, ${ }^{4}$ Tracey Goodman, ${ }^{4}$ Mark Young, ${ }^{5}$ Peggy Henderson, ${ }^{6}$ \\ Thomas Cherian ${ }^{4}$
}

'Department of Maternal Newborn Child and Adolescent Health, World Health Organization, Geneva, Switzerland

${ }^{2}$ Canadian Public Health Association, Ottawa, Canada

${ }^{3}$ Divonne, France

${ }^{4}$ Department of Immunization, Vaccines and Biologicals, World Health Organization, Geneva, Switzerland

${ }^{5}$ Child Health Team, United Nations Children's Fund, Three United Nations Plaza, New York, NY, USA

${ }^{6}$ Geneva, Switzerland

\section{Correspondence to} Dr Shamim Qazi, Department of Maternal, Newborn, Child and Adolescent Health, World Health Organization, 20 Avenue Appia, Geneva 27, 1211, Switzerland; qazis@who.int

Received 19 September 2014 Accepted 20 October 2014

\section{CrossMark}

To cite: Qazi $\mathrm{S}$

Aboubaker S, MacLean R,

et al. Arch Dis Child

2015;100(Suppl 1):s23-s28.

\section{ABSTRACT}

Despite the existence of low-cost and effective interventions for childhood pneumonia and diarrhoea, these conditions remain two of the leading killers of young children. Based on feedback from health professionals in countries with high child mortality, in 2009, WHO and Unicef began conceptualising an integrated approach for pneumonia and diarrhoea control. As part of this initiative, WHO and Unicef, with support from other partners, conducted a series of five workshops to facilitate the inclusion of coordinated actions for pneumonia and diarrhoea into the national health plans of 36 countries with high child mortality. This paper presents the findings from workshop and postworkshop follow-up activities and discusses the contribution of these findings to the development of the integrated Global Action Plan for the Prevention and Control of Pneumonia and Diarrhoea, which outlines the necessary actions for elimination of preventable child deaths from pneumonia and diarrhoea by 2025 . Though this goal is ambitious, it is attainable through concerted efforts. By applying the lessons learned thus far and continuing to build upon them, and by leveraging existing political will and momentum for child survival, national governments and their supporting partners can ensure that preventable child deaths from pneumonia and diarrhoea are eventually eliminated.

\section{INTRODUCTION}

Pneumonia and diarrhoea are two of the leading killers of young children. Of the estimated 6.3 million deaths among children under 5 years of age in 2013 , approximately $15 \%$ were caused by pneumonia and $9 \%$ by diarrhoea. ${ }^{1-3}$ Though considerable progress has been made towards the Millennium Development Goal (MDG) 4, which commits to reducing mortality of children under 5 years of age by 2015, it can only be achieved through intensified efforts focused on the leading causes of child mortality worldwide, including pneumonia and diarrhoea. Pneumonia and diarrhoea are caused by multiple pathogens, and therefore no single intervention can prevent and control either condition. However, low-cost and effective preventive and therapeutic interventions exist, many of which are common to both conditions.
In 2009, WHO and Unicef launched a plan for comprehensive diarrhoea control; during that same year, the Global Action Plan for Pneumonia Prevention and Control was also launched. ${ }^{45}$ While showing commitment for pneumonia and diarrhoea control was welcomed, health professionals from countries disproportionately affected by these two conditions expressed the need for more coordinated action. As a result, WHO and Unicef began conceptualising an integrated approach for pneumonia and diarrhoea control, emphasising the protection, prevention and treatment interventions that are common to these two conditions. As part of this initiative, WHO and Unicef, with support from various stakeholders, conducted a series of five multicountry workshops. The findings from these workshops informed the development of an integrated framework of key interventions for pneumonia and diarrhoea, culminating in the launch of the integrated Global Action Plan for the Prevention and Control of Pneumonia and Diarrhoea (GAPPD) in April 2013. ${ }^{6}$ This paper will discuss the major findings from the regional and country workshops, and will also highlight the contribution of these findings to the development of GAPPD and the ongoing implementation of pneumonia and diarrhoea control efforts. ${ }^{\mathrm{i}}$

\section{METHODS}

\section{Preworkshop preparation}

Prior to the workshops, country representatives under the leadership of the Ministry of Health $(\mathrm{MOH})$ were asked to conduct a situation analysis of existing childhood pneumonia and diarrhoea control efforts at the country level and to share lessons learned thus far in the implementation of key interventions.

\section{Workshops}

The five multicountry workshops were held in Kenya, Senegal, Bangladesh, Rwanda and Sudan between January 2011 and November $2012 .{ }^{i}$

${ }^{\mathrm{i}}$ Refer to the following source for a further discussion of the major barriers identified by workshop participants to the implementation of a coordinated response to childhood pneumonia and diarrhoea: Gill et al. ${ }^{10}$

${ }^{i i}$ Note that additional workshops were held in Togo and Denmark in November and December 2013, respectively. Although these workshops were held following the launch of GAPPD and, therefore, did not contribute to its 
These workshops were jointly organised and conducted by WHO and Unicef with support from the United States Agency for International Development (USAID), Maternal and Child Health Integrated Programme (MCHIP), Population Services International, the GAVI - The Vaccine Alliance and Save the Children. Funding for the workshops was provided by a grant from the Bill and Melinda Gates Foundation through WHO. Workshop participants included WHO and Unicef staff, as well as delegates working across various programmes and departments (eg, immunisation, nutrition, advocacy and communications) from 36 countries with high child mortality in the WHO regions of Africa, South-East Asia and the Eastern Mediterranean. Representatives from bilateral agencies, nongovernmental organisations and other development partners at the country, regional and global levels were also in attendance (refer to tables 1 and 2 for a complete list of workshop participants).

The primary objectives of the workshops were: (1) to engage countries in discussions of the burden of pneumonia and diarrhoea in children under 5 years of age and to underscore the necessity of a coordinated approach; (2) to promote cross-country learning by providing country delegates with an opportunity to share the findings from their respective situation analyses and (3) through country group sessions, to identify the major barriers to the implementation or scale-up of pneumonia and diarrhoea protection, prevention and treatment interventions and to develop a coordinated national action plan to scale up the use of all the appropriate interventions.

\section{Postworkshop follow-up}

After the regional workshops, WHO and Unicef engaged in regular communication with participating countries to monitor progress on agreed-upon action plans. Additionally, follow-up visits were conducted in Bangladesh, Burkina Faso, Kenya and Zambia by a multiagency team composed of representatives from WHO, Unicef, USAID and MCHIP.

\section{RESULTS}

\section{Preworkshop preparation}

Delegates from each country presented the findings from analyses of their respective situations, highlighting existing efforts being taken in respect of pneumonia and diarrhoea, as well as the major plans, opportunities, gaps and challenges for the key interventions. Among workshop countries, similar intervention-specific gaps were highlighted, including low coverage of exclusive breastfeeding; the need to introduce vaccines against rotavirus, Haemophilus influenzae type $\mathrm{b}$ and Streptococcus pneumoniae (pneumococcal conjugate vaccine, PCV) ${ }^{\mathrm{iii}}$; the need for increased action and intersectoral collaboration in several areas, including nutrition, water, sanitation, hygiene and the reduction of indoor air pollution; and inadequate or irregular supply of zinc and oral rehydration salts (ORS).

development, they nevertheless served to galvanise support for the coordinated prevention and control of childhood pneumonia and diarrhoea among workshop participants.

iii Note, however, that in many countries, plans were already under way to introduce new vaccines at the time of the workshops.

\section{Workshop discussions}

Barriers to the implementation and scale-up of pneumonia and diarrhoea interventions

Country representatives reported very similar barriers to the implementation and scale-up of pneumonia and diarrhoea interventions. Among the 36 countries represented in the workshops, the primary systematic barriers included lack of or outdated policies or strategies for child health and, more specifically, for community case management (CCM) and the administration of medicines and other consumables by community health workers $(\mathrm{CHW})$; poor coordination within and between programmes, departments and external partners, coupled with lack of intersectoral collaboration; insufficient engagement with the private sector; inadequate financial resources; human resource shortages, combined with a paucity of training opportunities for health personnel; poor logistics and supply chain management resulting in scarce or irregular supplies of key commodities; limited access to healthcare due to geographical and financial barriers; inadequate communication and social mobilisation; poor supervision and monitoring; non-availability or inadequate quality of data in the national health information systems; and poor integration of relevant indicators and/or community-level data into the health management information system (HMIS).

\section{Promising opportunities for prevention and control of pneumonia} and diarrhoea

During the workshops, country delegates reported very similar opportunities for prevention and control of pneumonia and diarrhoea, including political will to achieve the MDGs, strengthened by the Countdown to 2015 call to action; renewed interest in child survival resulting from several international commitments; accelerated expansion of primary healthcare facilities in some areas; introduction of new vaccines and resultant high visibility and momentum for the comprehensive control of pneumonia and diarrhoea; favourable environment for policy dialogue and change; and improved government financing mechanisms (eg, introduction of incentive mechanisms for CHWs).

\section{Knowledge sharing}

The workshops provided participants with an opportunity to share their experiences and to exchange best practices with representatives from other programmes and with delegates from countries confronted with similar obstacles. This sharing of best practices facilitated cross-programme and cross-country learning and, in many cases, provided a stimulus for accelerated action. For example, the experience of scaling-up CCM presented by Ethiopia provided a stimulus for Kenya to review its own policy on integrated CCM (iCCM), ultimately resulting in a more favourable environment for policy dialogue, especially with regards to the use of antibiotics by trained and supervised CHWs.

\section{Coordinated plans of action}

There was a high level of overlap between the coordinated plans of action developed by country teams. Country action plans focused on developing and/or updating policies and strategies, including those related to child health and CCM, as well as those concerning the administration of medicines and other consumables by $\mathrm{CHWs}$; advocating for increased support for child survival and pneumonia and diarrhoea; strengthening capacity for coordination between all programmes, departments and external partners involved in child survival, including those from outside the health sector; strengthening public-private 
Table 1 Participating countries: mortality rates and number of deaths from pneumonia and diarrhoea in children under the age of 5 years in 2013

\begin{tabular}{|c|c|c|c|c|}
\hline $\begin{array}{l}\text { Regional } \\
\text { workshop }\end{array}$ & $\begin{array}{l}\text { Participating } \\
\text { countries }\end{array}$ & $\begin{array}{l}\text { Mortality rate in children below the } \\
\text { age of } 5 \text { years in } 2013 \text { (deaths per } \\
1000 \text { live births) }\end{array}$ & $\begin{array}{l}\text { Number of deaths in children below } \\
\text { the age of } 5 \text { years from pneumonia } \\
\text { in } 2013\end{array}$ & $\begin{array}{l}\text { Number of deaths in children below } \\
\text { the age of } 5 \text { years from diarrhoea } \\
\text { in } 2013\end{array}$ \\
\hline Nairobi, Kenya & Ethiopia & 64 & 34565 & 18534 \\
\hline January 2011 & Ghana & 78 & 8095 & 4750 \\
\hline 108 & Kenya & 71 & 18576 & 10515 \\
\hline \multirow[t]{5}{*}{ participants } & Malawi & 68 & 5465 & 3003 \\
\hline & Nigeria & 117 & 120199 & 76938 \\
\hline & $\begin{array}{l}\text { United Republic of } \\
\text { Tanzania }\end{array}$ & 52 & 14263 & 7087 \\
\hline & Uganda & 66 & 15454 & 8383 \\
\hline & Zambia & 87 & 7550 & 4563 \\
\hline M'bour, & Benin & 85 & 4524 & 2798 \\
\hline Senegal & Burkina Faso & 98 & 9663 & 6417 \\
\hline May 2011 & Chad & 148 & 14157 & 10125 \\
\hline \multirow[t]{4}{*}{72 participants } & $\begin{array}{l}\text { Democratic Republic of } \\
\text { the Congo }\end{array}$ & 119 & 49598 & 33730 \\
\hline & Mali & 123 & 13180 & 9334 \\
\hline & Niger & 104 & 15256 & 10141 \\
\hline & Senegal & 55 & 3628 & 1866 \\
\hline Dhaka, & Bangladesh & 41 & 17655 & 8298 \\
\hline Bangladesh & Bhutan & 36 & 86 & 39 \\
\hline September & Democratic People's & 27 & 1633 & 533 \\
\hline 2011 & Republic of Korea & & & \\
\hline \multirow[t]{8}{*}{95 participants } & India & 53 & 177508 & 140451 \\
\hline & Indonesia & 29 & 22220 & 7505 \\
\hline & Maldives & 10 & 6 & 1 \\
\hline & Myanmar & 51 & 6960 & 3378 \\
\hline & Nepal & 40 & 3349 & 1554 \\
\hline & Sri Lanka & 10 & 232 & 72 \\
\hline & Thailand & 13 & 742 & 251 \\
\hline & Timor Leste & 55 & 408 & 214 \\
\hline Kigali, Rwanda & Angola & 167 & 26392 & 22465 \\
\hline October 2011 & Burundi & 83 & 6483 & 4094 \\
\hline \multirow[t]{6}{*}{63 participants } & Cote d'Ivoire & 100 & 10746 & 6985 \\
\hline & Cameroun & 95 & 12718 & 8497 \\
\hline & Madagascar & 56 & 7982 & 4096 \\
\hline & Rwanda & 52 & 3850 & 2028 \\
\hline & Guinea & 101 & 5571 & 3341 \\
\hline & Togo & 85 & 2894 & 1728 \\
\hline Khartoum, & Sudan & 77 & 17265 & 10507 \\
\hline Sudan & Somalia & 146 & 12144 & 8276 \\
\hline November & & & & \\
\hline 2012 & & & & \\
\hline 75 participants & & & & \\
\hline
\end{tabular}

partnerships; resolving existing human resource inadequacies through, for example, increased training opportunities or amelioration of recruitment and retention schemes; mobilising resources; ameliorating supply chain management; increasing access to healthcare and/or increasing coverage of relevant interventions; developing or strengthening communications and social mobilisation policies or strategies; increasing capacity for monitoring and supervision; and strengthening the HMIS.

\section{Advocacy and communications}

The sessions on communications and advocacy provided country representatives with an opportunity to develop the capacity required to advocate for a more coordinated response to pneumonia and diarrhoea control. Each country delegation went away from the workshop with a single, overarching communications objective, a better understanding of key stakeholders to be targeted and a series of targeted messages along with initial plans for advocacy and communications activities. These sessions were highly appreciated by workshop participants. In a follow-up to the workshop, Burkina Faso organised a capacity-building event for key experts involved in advocacy and communications and developed a national communications and advocacy strategy.

\section{Postworkshop actions}

Implementation of country action plans

Following the workshops, WHO and Unicef staff engaged in regular communication with all participating countries, the large majority of which reported continued progress towards the implementation of the actions identified in their national plans. For example, Ghana, among other countries, introduced PCV and rotavirus vaccines into routine immunisation and adapted the 'Pocket book of hospital care for children'; Ethiopia improved procurement and distribution of zinc and is preparing for domestic production; Niger developed a communications plan for child health and used World Pneumonia Day celebrations as a platform for further advocacy; and Burkina Faso celebrated World Pneumonia Day for the first time in 2012. 
Table 2 Countries represented in the workshop, venues and type of participants

Nairobi, Kenya, from 25 to 27 January 2011

Countries represented from AFRO*: Ethiopia, Ghana, Kenya, Malawi, Nigeria, Tanzania, Uganda and Zambia

Total participants: 108

Participating country government representatives

International agencies (WHO and Unicef)

Bilateral agencies (USAID, MCHIP)

Donor agencies (Bill and Melinda Gates Foundation and GAVI - The Vaccine Alliance)

NGOs (eg, AMREF, CHAI, PATH, Red Cross, World Vision, World Friends Kenya etc.)

Academic institutions (Johns Hopkins School of Public Health)

Other

M'bour, Senegal from 24 to 27 May 2011

Countries represented from AFRO*: Chad, Benin, Burkina Faso, Democratic Republic of Congo, Mali, Niger and Senegal Total participants: 72
Participating country government representatives

International agencies (WHO and Unicef)

Bilateral agencies (USAID, MCHIP, BASICS Malawi)

NGOs (MSH, Organisation Ouest Africaine de la Santé, PATH and World Vision)

Academic institutions (Université Cheikh Anta Diop de Dakar)

Dhaka, Bangladesh from 27 to 29 September 2011

Countries represented from SEAROt: Bangladesh, Bhutan, Democratic People's Republic of Korea, India, Indonesia, Maldives, Myanmar, Nepal, Sri Lanka, Thailand and Timor-Leste

Total participants: 95
Participating country government representatives

International agencies (WHO and Unicef)

Bilateral agencies (USAID, MCHIP, MCH STAR and NIPI)

Donor agencies (Bill and Melinda Gates Foundation)

NGOs (Save the Children and Swaasthya)

Academic institutions (Johns Hopkins School of Public Health and Aga Khan University)

Healthcare representatives (both public and private healthcare)

Professional associations

WHO Collaborating Centre representatives

Other

\section{Kigali, Rwanda from 25 to 28 October 2011}

Countries represented from AFRO*: Angola, Burundi, Cameroun, Cote d'Ivoire, Guinea, Madagascar, Rwanda and Togo Total participants: 63
Participating country government representatives International agencies (WHO and Unicef)

Bilateral agencies (USAID and MCHIP)

Donor agencies (Bill and Melinda Gates Foundation)

NGOs (World Vision)

\section{Khartoum, Sudan from 11 to 13 November 2011}

Countries represented from EMRO¥: Somalia and Sudan Total participants: 75
Participating government representatives

International agencies (WHO and Unicef)

Academic institutions (eg, Benadir University)

NGOs (Plan Sudan, Save the Children)

${ }^{*}$ AFRO: WHO Africa regional office.

+SEARO: WHO South East Asia regional office.

ҒEMRO: WHO Eastern Mediterranean regional office.

MCHIP, Maternal and Child Health Integrated Programme; NGO, non-governmental organisation; USAID, USA Agency for International Development.

Considerable progress has also been observed in Zambia and Bangladesh. Following the workshops, the $\mathrm{MOH}$ identified priority districts as demonstration sites for the implementation of coordinated actions for the prevention and control of pneumonia and diarrhoea. In both countries, district implementation plans were developed highlighting key activities, including retraining healthcare workers and CHWs, improving supply chain and logistics, implementing combined quality care approaches and increasing advocacy in the wake of introduction of new vaccines. Partners in Bangladesh and Zambia are working hand in hand to support their respective implementation plans. For example, both countries are planning to upgrade existing Oral Rehydration Corners to Child Health Corners to facilitate 'one-stop' delivery of integrated services. A monitoring and evaluation system has been put in place in both countries to assess the outcomes (coverage, morbidity, mortality) of these coordinated actions as well as best practices and lessons learned. More recently, in October 2014, the Government of India hosted a workshop for four states to facilitate the implementation of coordinated actions for the prevention and control of pneumonia and diarrhoea in 16 districts.

The implementation of many of the activities outlined in country action plans has, in many cases, also had far-reaching impacts for child health more broadly. For example, the introduction of new vaccines in many countries has been accompanied with comprehensive training of health workers on vaccine-preventable disease control and integrated case management, in addition to promotion of other child health interventions. Myanmar immunisation days, for example, were used to distribute soap and to promote hand washing as well as exclusive breastfeeding.

\section{Postworkshop follow-up visits}

The follow-up visits conducted in select countries were very beneficial; at the international level, they served to solidify existing partnerships and reinforce previous commitments to child survival, and pneumonia and diarrhoea control more specifically. At the country level, these visits facilitated progress towards 
agreed-upon action plans and towards implementation of a more coordinated response to pneumonia and diarrhoea. For example, the visit to Kenya led to the identification of barriers to scale-up that could be addressed through implementation research. As a result, an implementation research priority-setting workshop was organised in Kenya which, in turn, led to the funding of two research proposals focused on identifying the most effective mechanisms for scale-up of key interventions, including iCCM.

Additionally, country follow-up visits facilitated the identification of existing gaps in relevant tools and guidelines. For example, in response to identified gaps, a Planning Handbook for Countries to Introduce and Scale up Caring for Newborns and Children in the Community was developed by WHO in collaboration with Unicef, Save the Children, USAID and others, and has been successfully field tested in Liberia. The handbook is set to be released by the end of 2014. Finally, visits presented opportunities to leverage additional resources; during the follow-up visits, a number of partners committed to provide further resources in order to support countries in implementing national plans of action. For example, World Vision pledged to support iCCM in Kenya.

\section{DISCUSSION}

The regional and country workshops and subsequent follow-up support provided the necessary impetus for accelerated action on pneumonia and diarrhoea. Since the workshops, the majority of participating countries have made considerable progress in implementing the actions outlined in their coordinated plans. This initiative also facilitated the coming together of professionals from different programmes and departments at both regional and country levels. Following the workshops, many countries developed and/or reinvigorated mechanisms for increased coordination, ultimately leading to greater synergies and efficiencies at the country level. At the international level, the workshops served to unite a broad range of stakeholders jointly committed to the elimination of preventable childhood deaths resulting from pneumonia and diarrhoea. The benefits of these partnerships are far-reaching. For example, the linkages formed during workshop preparations facilitated the reorganisation of the global iCCM Task Force, composed of Unicef, WHO, USAID and Save the Children, among others, which, in turn, has enabled the harmonisation of tools, guidelines and approaches for iCCM, as well as the identification of opportunities for joint action. Moreover, the newly launched Every Newborn: An Action Plan to End Preventable Deaths ${ }^{8}$ was developed based upon many of the lessons learned from and the GAPPD process.
The consolidation of national and international partnerships for child survival, coupled with the valuable insight provided by country delegates during workshop sessions and postworkshop follow-up were critical to the development of an integrated approach for pneumonia and diarrhoea. Following the workshops, the framework of key protection, prevention and treatment interventions was refined by WHO and Unicef (see figure 1) and the need for an integrated global action plan was identified, ultimately leading to the launch of GAPPD in April 2013. GAPPD provides national governments and their partners with an integrated framework of key interventions for pneumonia and diarrhoea control. Although most countries are already implementing at least some of these measures, coverage is uneven and service delivery remains uncoordinated. ${ }^{9}$ The GAPPD, therefore, outlines a clear set of priorities and actions for the coordinated implementation and scale-up of these key interventions and aims to facilitate and monitor country progress towards the ultimate goal of ending preventable childhood deaths due to pneumonia and diarrhoea by 2025 .

The lessons learned, as well as the best practices identified during workshop and postworkshop follow-up activities must be continuously applied in order to support national governments in implementing the actions outlined in GAPPD and in further progressing toward MDG 4. Moving forward, several challenges remain. ${ }^{10}$ Lack of coordination and intersectoral collaboration, shortage of human resources, insufficient financial resources, inadequate access to healthcare, poor logistics and supply chain management, inadequate supervision and poor health information systems are barriers that must be overcome. Many of these barriers are not unique to pneumonia and diarrhoea interventions, but rather permeate health service delivery in low-resource settings. As such, the implementation of local solutions to the identified barriers can contribute to the strengthening of the health system more broadly, on condition that efforts are carried out in collaboration with all relevant stakeholders. Moreover, delivery platforms created by the implementation and scale-up of preventive and therapeutic interventions for pneumonia and diarrhoea can facilitate a reduction in inequitable access to healthcare, particularly if community-based platforms are used to reach those most in need. ${ }^{11}$

Eliminating child deaths resulting from pneumonia and diarrhoea by 2025 as outlined in GAPPD may seem overly ambitious given the global burden of pneumonia and diarrhoea and the seemingly pervasive nature of the aforesaid barriers to service delivery. But on the contrary, this goal is both necessary and attainable, and several recent advancements in child survival and pneumonia and diarrhoea control should be celebrated.

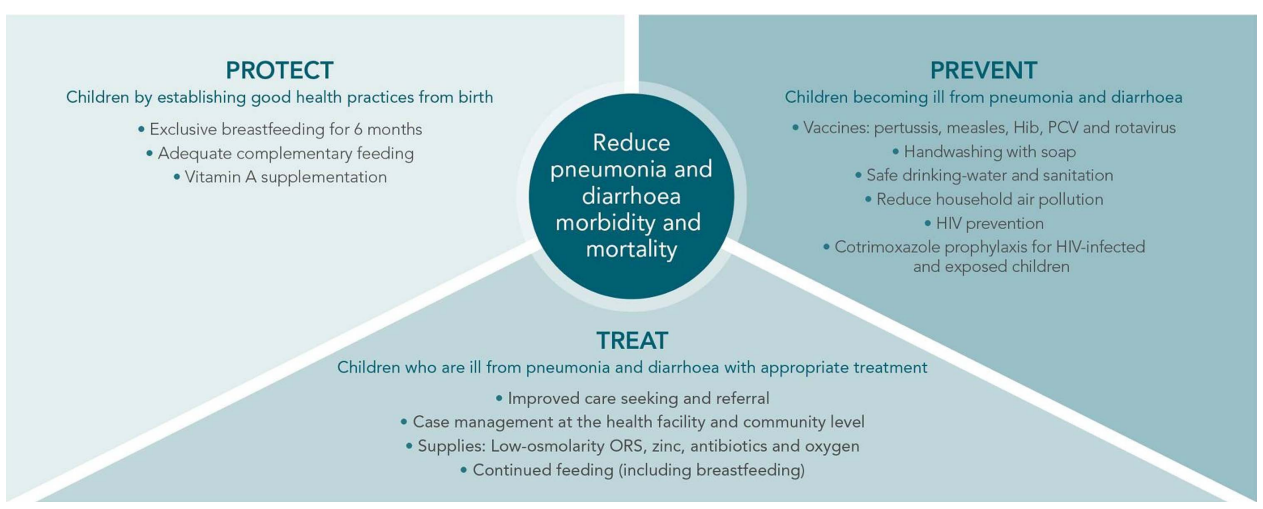

Figure 1 Protect, prevent and treat framework. ${ }^{6}$ ORS, oral rehydration salts; PCV, pneumococcal conjugate vaccine; Hib, Haemophilus influenzae type b. 
For example, by September 2014, Haemophilus influenzae type b-containing vaccines, PCV and rotavirus vaccines, had been introduced into the national immunisation programmes of 191, 111 and 69 countries, respectively. ${ }^{12}$ Moreover, many of the 75 countries with high child mortality that are part of the Countdown to 2015 initiative are on track to reach MDG $4 .^{13}$

The international commitments that position child survival at the forefront of the global health and development agenda and that embrace multisectoral collaboration provide unprecedented opportunities for pneumonia and diarrhoea control, including the Every Woman Every Child umbrella movement and the United Nations Global Strategy for Women's and Children's Health; ${ }^{14}$ the Diarrhea and Pneumonia Treatment Working Group for the United Nations Commission on Life-Saving Commodities for Women and Children ${ }^{15}$ specifically tasked to accelerate uptake of amoxicillin, ORS and zinc for treatment of childhood pneumonia and diarrhoea; the Unicef and USAID call to action Committing to Child Survival: A Promise Renewed; ${ }^{16}$ the Global Vaccine Action Plan 2011-2020; ${ }^{17}$ the United Nations Sustainable Energy for All initiative; ${ }^{18}$ the Global Fund New Funding Model that provides a key opportunity for increased integration of pneumonia and diarrhoea treatment with malaria grants; and the United Nations Commission on Information and Accountability. ${ }^{19}$

Though the GAPPD goal of eliminating preventable child deaths from pneumonia and diarrhoea by 2025 is ambitious, it is entirely achievable. To reach this goal, all stakeholders must work together to increase political will for eliminating pneumonia and diarrhoea, foster intersectoral collaboration, increase efficiency through prioritisation of interventions based on local context, increase investments in health policy and systems research, and strengthen accountability for results and resources. ${ }^{20}$ Without concerted action in these priority areas, large numbers of children will continue to die from pneumonia and diarrhoea despite the existence of effective interventions. Complacency is, therefore, not an option. In the drive to implement GAPPD and reach MDG 4, national governments and their supporting partners need to apply the lessons learned thus far and continue to build upon them to ensure that preventable child deaths from pneumonia and diarrhoea are ultimately eliminated.

\section{Competing interests None.}

Provenance and peer review Commissioned; internally peer reviewed.

\section{REFERENCES}

1 United Nations Inter-agency Group for Child Mortality Estimation. Levels and trends in child mortality: report 2014. New York, UNICEF, 2014.

2 Liu L, Oza S, Hogan D, et al. Global, regional, and national causes of child mortality in 2000-13, with projections to inform post-2015 priorities: an updated systematic analysis. Lancet 2014 (published online).

3 WHO. Global Health Observatory. Causes of child mortality. http://www.who.int/ gho/child_health/mortality/causes/en/ (accessed 17 Sep 2014).

4 WHO, UNICEF. Diarrhoea: why children are still dying and what can be done. New York, UNICEF and WHO, 2009. http://whqlibdoc.who.int/publications/2009/ 9789241598415_eng.pdf

5 WHO, UNICEF. Global Action Plan for Prevention and Control of Pneumonia (GAPP). Geneva, WHO, 2009. http://whqlibdoc.who.int/hq/2009/WHO_FCH_CAH_ NCH_09.04_eng.pdf

6 WHO/UNICEF. Ending preventable child deaths from pneumonia and diarrhoea by 2025: The integrated Global Action Plan for Pneumonia and Diarrhoea. Geneva, WHO, 2013.

7 WHO. Pocket book of hospital care for children: Guidelines for the management of common illnesses with limited resources. 2nd edn. Geneva: WHO, 2013.

8 WHO. Every Newborn: an action plan to end preventable deaths. South Africa: WHO, 2014. http://apps.who.int/iris/bitstream/10665/127938/1/9789241507448_ eng.pdf ?ua=1

9 WHO, UNICEF. Countdown to 2015. Building a future for women and children: The 2012 report. Washington, 2012.

10 Gill CJ, Young M, Schroder K et al. Bottlenecks, barriers, and solutions: results from multicountry consultations focused on reduction of childhood pneumonia and diarrhoea deaths. Lancet 2013;381:1487-98.

11 Bhutta ZA, Das JK, Walker N, et al. Interventions to address deaths from childhood pneumonia and diarrhoea equitable: what works and at what cost? Lancet 2013;381:1417-29.

12 WHO. Immunization Repository. https://extranet.who.int/immunization_repository/

13 Kuruvilla S, Schweitzer J, Bishai D, et al. Success factors for reducing maternal and child mortality. Bull World Health Organ 2014;92:533-44.

14 United Nations Secretary General. Global strategy for women's and children's health. Geneva, Partnership for Maternal, Newborn and Child Health, 2012.

15 United Nations. United Nations Commission on Life-Saving Commodities for Women and Children. Implementation Plan. New York, United Nations, 2012. http://www.everywomaneverychild.org/images/Implementation_plan_Sept_2012. pdf

16 UNICEF, USAID. Committing to child survival: a promise renewed. New York, UNICEF, 2012. Brochure available at: http://www.apromiserenewed.org/Brochure. $\mathrm{html}$

17 WHO. Global Vaccine Action Plan 2011-2020. USA: WHO, 2013.

18 United Nations Secretary General. Sustainable Energy for All. A Vision Statement by Ban Ki-Moon, Secretary General of the United Nations. New York, United Nations, 2011.

19 Commission on Information and Accountability for Women's and Children's Health. Keeping promises, measuring results. Geneva: WHO, 2011. http://www. everywomaneverychild.org/images/content/files/accountability_commission/final report/Final_EN_Web.pdf

20 Chopra M, Mason E, Borrazzo J, et al. Ending of preventable deaths from pneumonia and diarrhoea: an achievable goal. Lancet 2013;381:1499-506. 